\title{
Green Synthesis of Copper Nanoparticles Using Mitragyna Parvifolia Bark Extract and its Antimicrobial Study
}

\author{
Shaileshkumar C Kotval, Kokila A Parmar \\ Hemchandracharya North Gujarat University, Patan, Gujarat, India
}

\begin{abstract}
In this study, Mitragyna parvifolia plant bark an aqueous extract which provides cost-effective, eco-friendly process, less time consuming, an environmentally benign, easy and proficient way for the synthesis of copper nanoparticles. Mitragyna parvifolia plant bark was collected from virpur hills forest area. The Mitragyna parvifolia plant bark extract was prepared in de-ionised water and used for the green synthesis of copper nanoparticles. The color change of the solution dark brown from pale yellow colored, this confirms that there is a formation of copper nanoparticles. The green synthesised copper nanoparticles were characterized by UVVisible spectroscopy, FT-IR, XRD, SEM, TEM and their antimicrobial activity was investigated. From UVVisible spectrophotometer result was confirmed the reduction of copper sulphate to copper nanoparticles. FTIR analysis was confirmed the bending vibrations and stretching bonds present in the sample. Spherical shape was finding out by XRD and the size of the particle was analyzed with the help of Scanning Electron Microscopy. The antibacterial activity experiment against Escherichia coli gram-negative and Bacillus subtilis gram-positive bacteria by agar well method and the maximum zone of inhibition was higher in gram-positive bacteria compared to gram-negative bacteria. The green synthesised copper nanoparticles proved to be potential candidates for medical application antimicrobial activity is highly essential.
\end{abstract}

Keywords : Copper nanoparticles, Green synthesis, UV, FTIR, XRD, SEM, TEM, Antimicrobial Activity

\section{INTRODUCTION}

Nanotechnology has involved many researchers from different field like chemistry, physics, biotechnology, material science, engineering, medicine, pharmaceutical etc. Copper Nanoparticles synthesised by many ways such as biological method, chemical method, physical method, sol-gel method, solid-state reaction, co-precipitation, vapour deposition ${ }^{1}$, electrochemical reduction ${ }^{2}$, radiolysis reduction ${ }^{3}$, thermal decomposition ${ }^{4}$ and chemical reduction of copper metal salt ${ }^{5}$. green synthesis method has so many advantages compared to other methods and one of the best method because it is cost-effective, simple, use of low energy, use of less toxic materials and eco- friendly ${ }^{6-7}$. The copper nanoparticles are mostly found their applications in the field of medical, electronic devices, biosensors, and reagents in various reactions, lubricants, antibiotic, antimicrobial agents and many more.

The Mitragyna parvifolia is a tree belongs to Rubiaceae family, plant species are used medicinally and their height of 50 feet with a branch spread over 15 feet and a stem is erect and branching, flowers are yellow and grow in ball-shaped clusters, dark green in colour leaves smooth and round in shape ${ }^{8}$. The Medicinal plant has contained a variety of phytopharmaceuticals found very important applications of in the area of agriculture, human and 
veterinary medicine and novel drug for the treatment and prevention of disease'. The plant bark and roots are used in the treatment of fiver, colic, muscular pain, burning sensation, poisoning, gynaecological disorders, cough, oedema and fruit juice augments the breast milk in lactating mothers ${ }^{10}$.
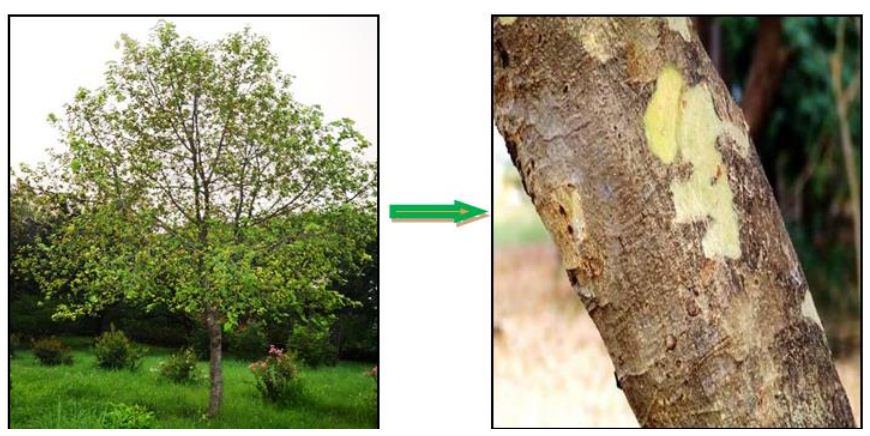

Fig.1 Bark of Mitragyna parvifolia plant

\section{METHODS AND MATERIAL}

\subsection{MATERIALS}

The plant Mitragyna parvifolia material was collected from Virpur hills and forest, sabarkantha district, Gujarat. Ultra-pure deionised water used in entire research. Analytical A grade copper sulphate was purchased Sigma-Aldrich Chemicals.

\subsection{PREPARATION OF M. PARVIFOLIA BARK EXTRACT}

Collected plant bark first washes tap water then again washes with double distilled water and dry it at room temperature for 15-20 days. After dried bark, it was converting into powder form by using a grinder and collects it in neat and clean dry air tight bottle for use of research. Weigh $10 \mathrm{gm}$ of powder takes in $250 \mathrm{ml}$ conical flask and add $100 \mathrm{ml}$ deionised water after that conical flask put on magnetic stirrer and stir for $30 \mathrm{~min}$ at $60 \mathrm{oC}$. The extract was cool down at room temp and filtered with whatman no.1 filter paper and the filtrate obtained was store at room temp at the dark place for further use.

\subsection{SYNTHESIS OF COPPER NANOPARTICLES}

The reaction mixture was prepared by $10 \mathrm{ml}$ of $\mathrm{M}$. parvifolia extract was added to $90 \mathrm{ml}$ of an aqueous copper sulphate solution in a $250 \mathrm{ml}$ conical flask. After that, the solution colour changed pale yellow from blue when the solution of M. parvifolia extract and copper sulphate were stirred on the magnetic stirrer for a homogeneous mixture. After that, the flask was kept at room temperature for incubation around 24 hours and the colour was changed turn into dark brown from pale yellow11.

\subsection{PURIFICATION OF COPPER NANOPARTICLES}

The reaction mixture was centrifuged at $10,000 \mathrm{rpm}$ for $15 \mathrm{~min}$ followed by dispersion of the pellet in deionised water and the CuNPs were dried in an oven at $80 \mathrm{oC}$ for $4-5$ hours 12 .

\subsection{CHARACTERIZATION OF PREPARED COPPER NANOPARTICLES}

\subsubsection{UV-VISIBLE SPECTROPHOTOMETER} ANALYSIS

The green synthesized CuNPs characterization was monitored by Shimadzu 1800 UV-Visible spectrophotometer in the wavelength range of 300$700 \mathrm{~nm} .2 \mathrm{~mm}$ caveat and double distilled water were utilized for blank reading.

\subsubsection{FT-IR SPECTROSCOPY ANALYSIS}

The Fourier Transform Infrared spectra were identified by an FT-IR spectrophotometer (Perkin Elmer Spectrum) using $\mathrm{KBr}$. The sample powder was 
mixed with $\mathrm{KBr}$ and prepared pallet scanned at the range of $4000-450 \mathrm{~cm}-1$.

\subsubsection{X-RAY DIFFRACTION (XRD) ANALYSIS}

The X-ray diffraction was used to obtaining the crystalline structure and data in the $2 \theta$ range of $20 \mathrm{o}-$ 80o.

The Debye Scherrer formula,

\section{$D=k N \beta \cos \theta$}

Where,

$\mathrm{D}=$ particle diameter size

$\mathrm{K}=$ constant equals 1

$\lambda=$ wavelength of $X$-ray source

$\beta=$ the full width at half maximum of the diffraction peak

$\theta=$ the Bragg angle

\subsubsection{SCANNING ELECTRON MICROSCOPY (SEM) ANALYSIS}

The surface morphology of CuNPs was analyzed by scanning electron microscope it was performed by SIGMA model and an operating on the voltage of 20 $\mathrm{kV}$ and for operation need a very small amount of dry powder sample put on a grid and removed excess sample with the help of blotting paper.

\subsubsection{TRANSMISSION ELECTRON MICROSCOPY (TEM) ANALYSIS}

TEM analysis characterizes the size, shape and morphology of the copper nanoparticles and a prepared sample was dried under vacuum in desiccators before placing it in a specimen holder. A thin sample was irradiated with a sharp high-energy electron beam focused by magnetic lance and electron intensity distribute on the beam after interaction with sample and image was recorded by digital camera and display on a computer screen 17.

\subsection{ANTIMICROBIAL ACTIVITY}

2.6.1. TEST ORGANISM FOR ANTIBACTERIAL ACTIVITY

In this study, two type bacteria were collected from the microbiology department, HNGU. One was gram-positive bacteria and another one was gramnegative, Bacillus subtilis (+ve) and Escherichia coli (ve). The bacterial strains were grown and maintained on nutrient agar at $380 \mathrm{C}$ in incubation condition for 5 days and the culture was stored at $4 \mathrm{oC}$ for further experiment work.

\subsubsection{MEDIA PREPARATION}

In the media preparation, B. subtilis and E. coli bacteria were grow in a nutrient agar medium. 2.8 gm nutrient agar powder was added into $100 \mathrm{ml}$ of distilled water for nutrient agar preparation then the prepared medium was kept in the cotton-plugged glass container and sterilized in the autoclave at 120 oC for $20 \mathrm{~min}$.

\subsubsection{METHOD FOR TESTING ANTIMICROBIAL} ACTIVITY OF SYNTHESISED COPPER NANOPARTICLES

Antimicrobial activity of green synthesised copper nanoparticles was carried out by agar disc diffusion method 13-15 against B. subtilis (+ve) and E. coli (-ve) bacteria.

The nutrient agar plates were prepared by $20 \mathrm{ml}$ for each of molten media into sterile Petri-plates. Plates were left standing for 10 minutes to let the culture get absorbed.

Using the micro-pipette, $100 \mu$ of the sample of Nanoparticles suspension was poured into different concentration $(25 \mu \mathrm{l}, 50 \mu \mathrm{l}, 75 \mu \mathrm{l})$ into each plate. Then Antibiotic-Ampicillin drug was used as positive 
control. After adding the samples in the wells, the dishes were kept in a refrigerator for an hour for absorption of the samples into the surrounding medium from the well. The plates were transferred into an incubator set at $37^{\circ} \mathrm{C}$ to allow bacterial growth on the medium. After 24 hrs the plates were taken out of the incubator and observed for the zone of bacterial growth inhibition around the wells. The zone of inhibition was measured in millimeters 16.

\section{RESULTS AND DISCUSSION}

\subsection{Color change}
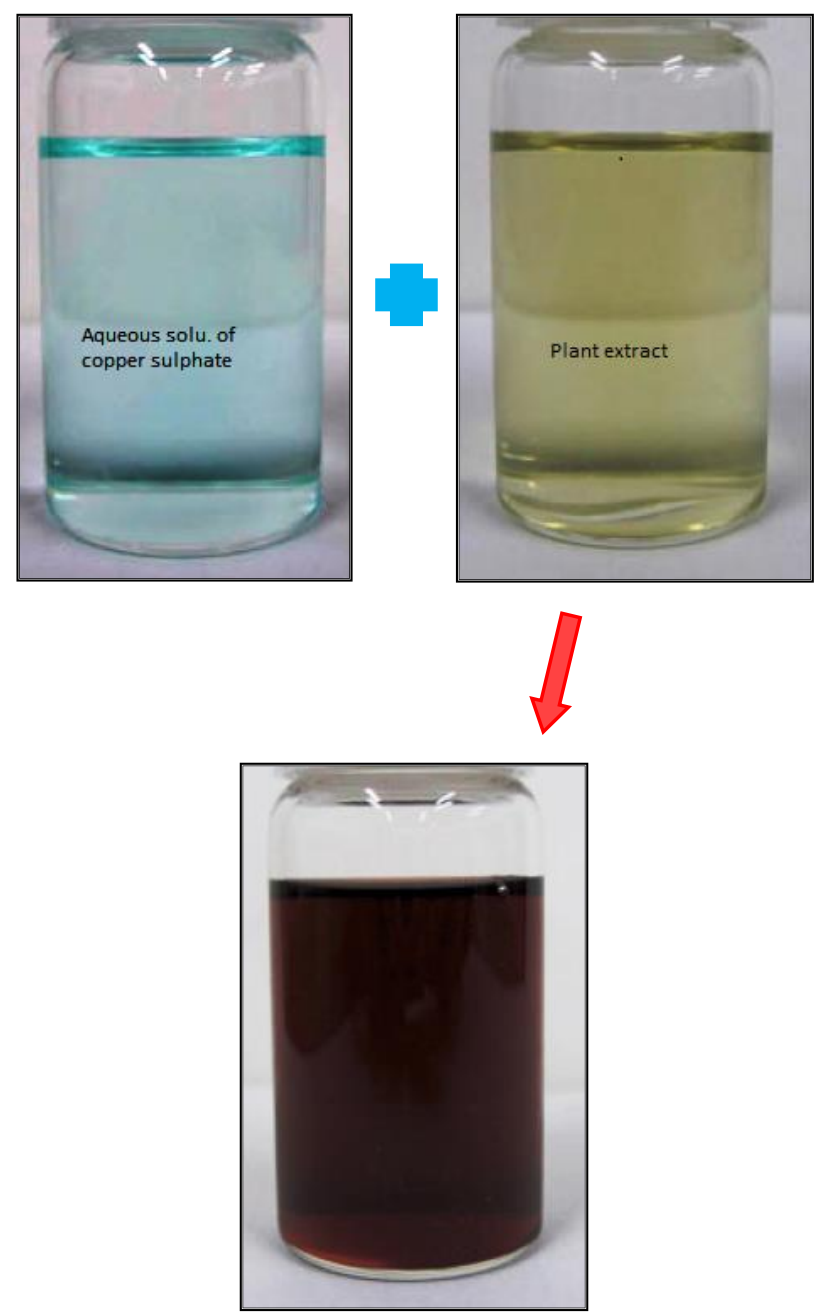

Fig. 2 Aqueous solu. of copper sulphate + plant extract $=$ after synthesis of CuNPs

\subsection{UV-visible Spectroscopy}

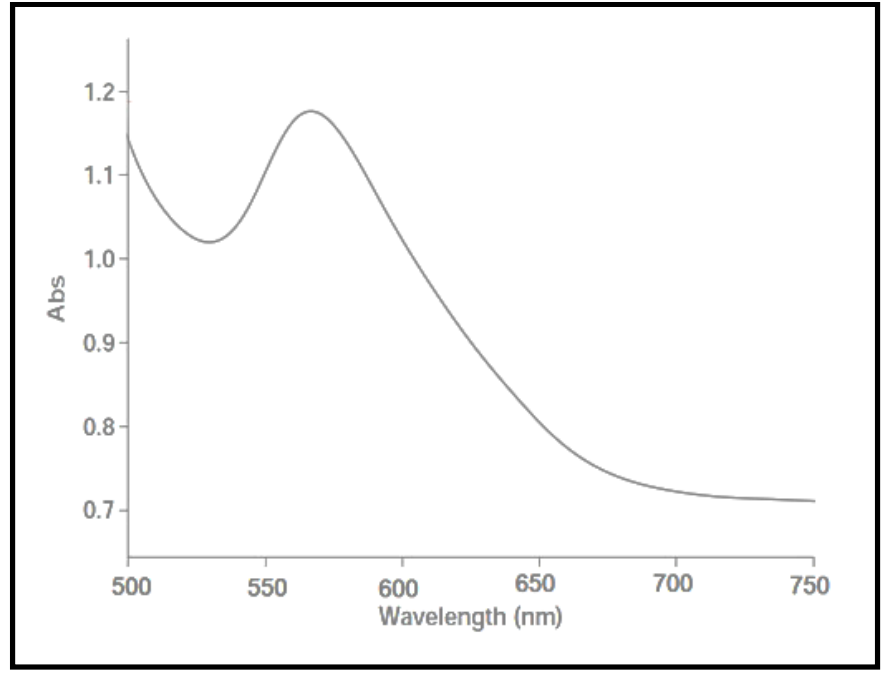

Fig. 3. UV-visible spectra of copper Nanoparticles

The characterization of copper Nanoparticles by UVVis spectra from the range of $500-750 \mathrm{~nm}$ the absorption spectra were obtained at $565-570 \mathrm{~nm}$ in graph represent.

\subsection{Fourier Transform Infrared Spectroscopy (FTIR)}

FTIR gives the information about present functional groups in synthesised copper nanoparticles and it shows in (fig. 4) clearly. In the spectra the peak at $3298.28 \mathrm{~cm}^{-1}$ and $3324.21 \mathrm{~cm}^{-1}$ indicating the presence of $-\mathrm{NH}$ or $-\mathrm{OH}$ group stretching in amino acids alcohols and phenols, Stretching at $2926.01 \mathrm{~cm}^{-1}$ corresponds to $\mathrm{C}-\mathrm{H}$ stretching in alkanes and aldehydes, stretching at $1648.12 \mathrm{~cm}-1$ indicate the presence of $>\mathrm{C}=\mathrm{O}$ group and the peak at $1103.28 \mathrm{~cm}^{-1}$ corresponds to $\mathrm{C}-\mathrm{O}$ stretching and the weak peaks in between $850.61 \mathrm{~cm}^{-1}$ to $526.57 \mathrm{~cm}^{-1}$ are associated to halo compounds stretching ${ }^{18-19}$. Hence these observations indicated the formation of CuNPs associated with metabolites protein like terpenoids contain functional groups as alcohols, phenols aldehydes, ketones and carboxylic acids. Kulkarni et al reported the bio-entities could probably play a double role of fabrication and stabilization of copper nanoparticles in the aqueous solution ${ }^{20}$. 


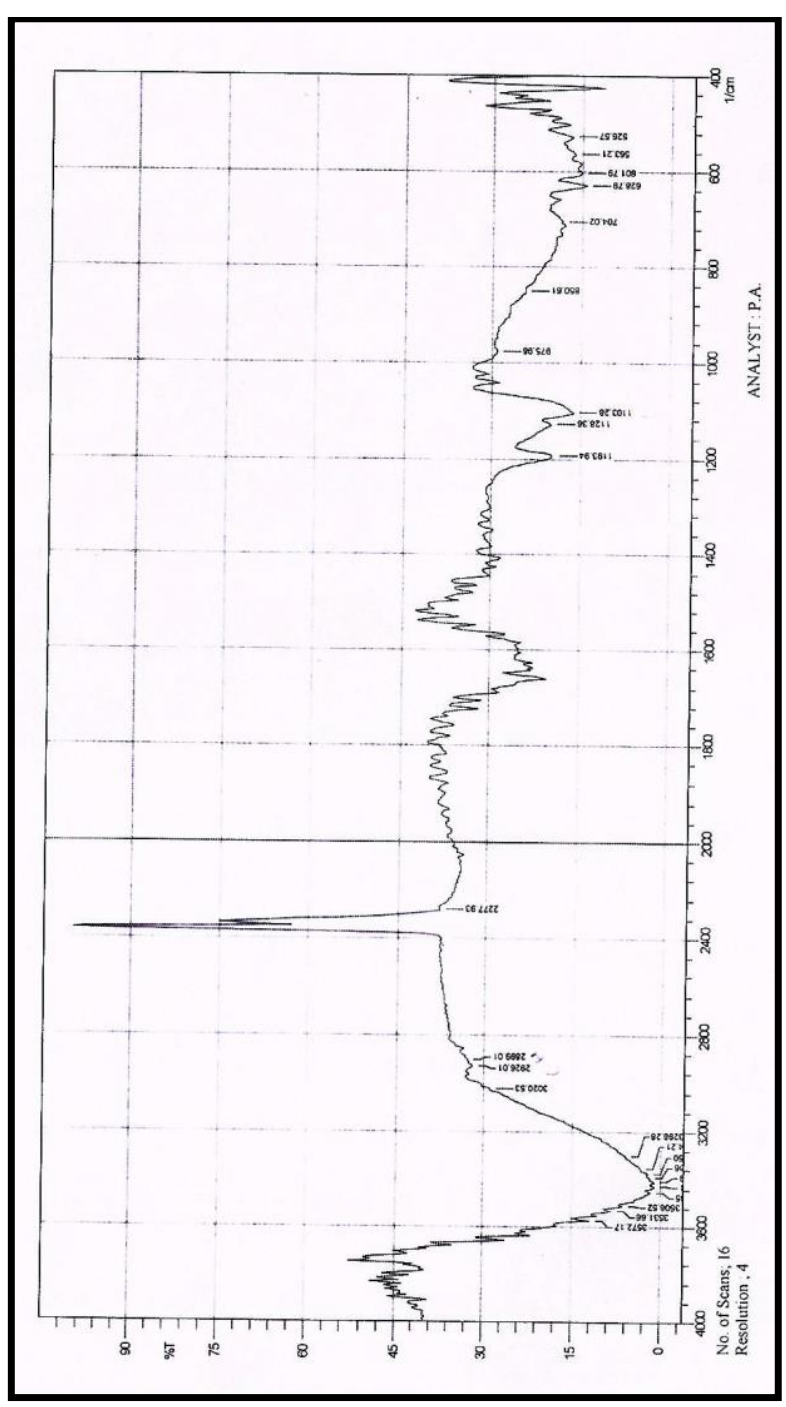

Fig. 4. FTIR spectra of copper nanoparticles

\subsection{X-ray diffraction}

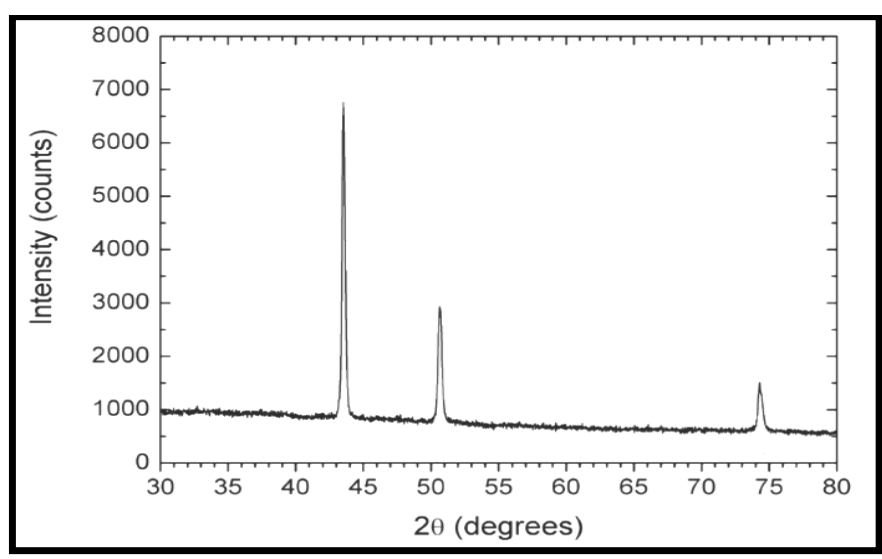

Fig.5. X-ray diffraction pattern of copper nanoparticles

In the X-ray diffraction study all the peaks observed $2 \theta$ value at $43.31^{\circ}, 50.55^{\circ}$ and $74.27^{\circ}$ representing the
(111), (200), and (220), morphology of the interplanar distance spacing was calculated by using Bragg's equation.

\subsection{Scanning Electron Microscopy SEM analysis}

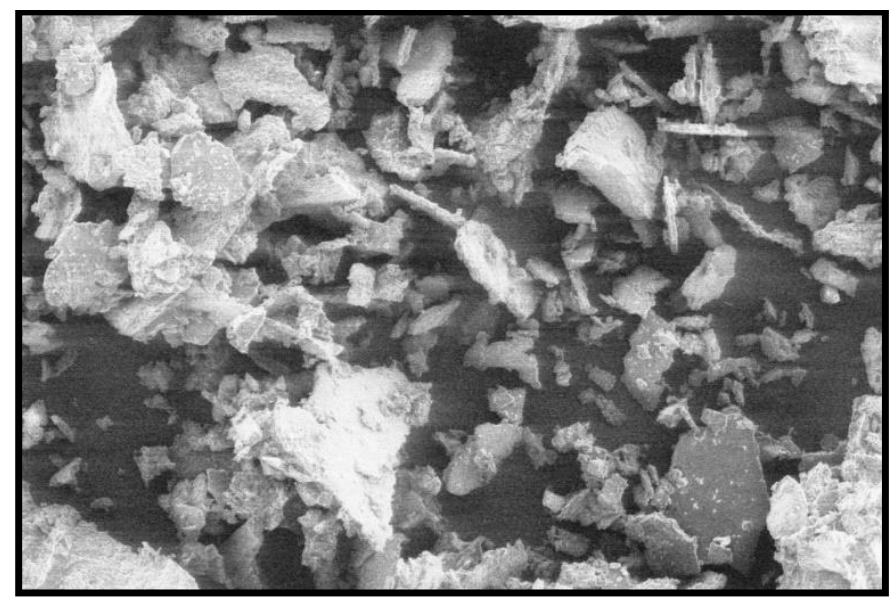

Fig.6. SEM analysis of copper nanoparticles

The copper nanoparticles size determined by scanning electron microscope image, in the surface morphology study of CuNPs average size was 23.6 $41.2 \mathrm{~nm}$; (fig. 6) shows the existence of symmetrical spherical shape. The electronic interaction and hydrogen bond between the bio-organic molecules bond are responsible for the synthesis of copper nanoparticles using plant extract ${ }^{21}$.

\subsection{Transmission Electron Microscopy (TEM) analysis}

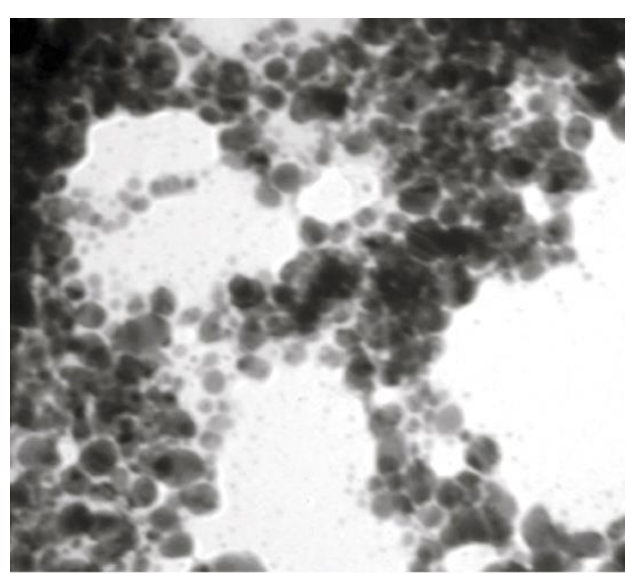

Fig.7. TEM analysis of copper nanoparticles 
The image of Silver nanoparticles synthesised using an aqueous extract of (plant name) shown in (fig. 7) the synthesized CuNPs was spherical in shape and an average diameter of 12-23 $\mathrm{nm}$. Singh et al have reported a similar geometry of synthesized silver and gold nanoparticles using natural precursor clove ${ }^{22}$.

\subsection{Antimicrobial activity}

The antimicrobial activity of green synthesised copper nanoparticles against two human pathogenic bacteria such as Bacillus subtilis and Escherichia coli. Here Bacillus subtilis is gram +ve and Escherichia coli is gram -ve bacteria were evaluated and compared to a commercial antibiotic drug ampicillin. Synthesised CuNPs showed the clear diameter of the zone of inhibition around the well wherein the suspension of CuNPs was applied. The obtained result was presented in table (A) and figure 8 .

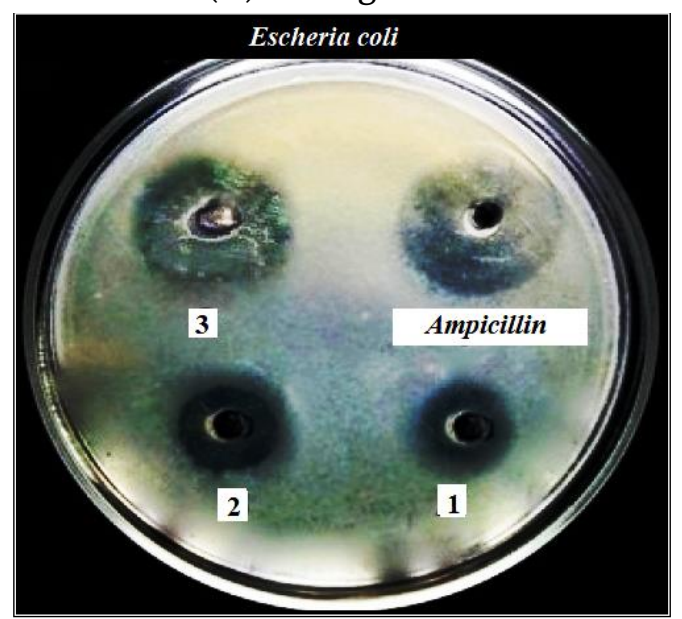

(a)

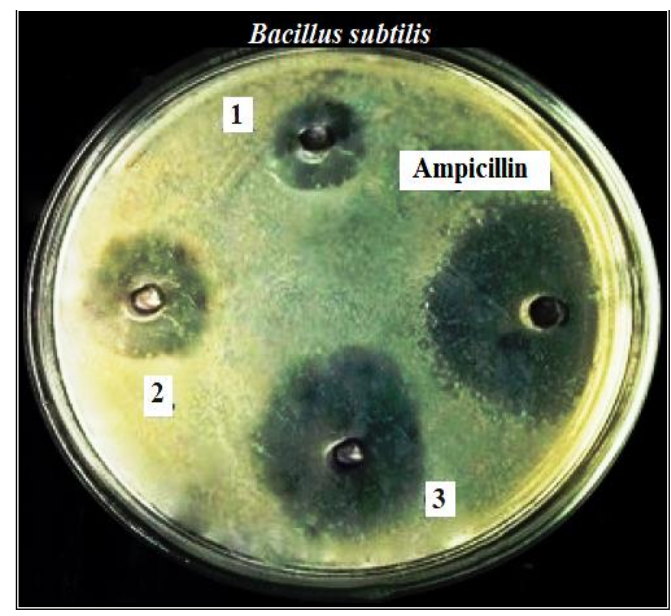

(b)
Fig. 8. antibacterial activities of CuNPs (a)

Escherichia coli and (b) Bacillus subtilis compared to a commercial antibiotic drug Ampicillin drug

Table (a). The Zone of inhibition area ( $\mathrm{mm}$ ) exhibited by the formed CuNPs against pathogenic bacteria

\begin{tabular}{|l|l|l|}
\hline $\begin{array}{l}\text { Concentration } \\
(\mu \mathrm{l})\end{array}$ & \multicolumn{2}{|l|}{$\begin{array}{l}\text { Diameter of zone of inhibition } \\
(\mathrm{mm})\end{array}$} \\
\cline { 2 - 3 } & $\begin{array}{l}\text { Escherichia } \\
\text { Coli }\end{array}$ & $\begin{array}{l}\text { Bacillus } \\
\text { Subtilis }\end{array}$ \\
\hline $25 \mu \mathrm{l}$ & 6.80 & 9.50 \\
\hline $50 \mu \mathrm{l}$ & 10.00 & 13.80 \\
\hline $75 \mu \mathrm{l}$ & 13.80 & 17.50 \\
\hline $\begin{array}{l}\text { Standard Drug } \\
\text { Ampicillin }\end{array}$ & 16.00 & 20.00 \\
\hline
\end{tabular}

\section{CONCLUSION}

In this study, green synthesis of copper Nanoparticles was successfully synthesized by using Mitragyna parvifolia plant bark an aqueous extract which provides cost-effective, eco-friendly process, less time consuming, an environmentally benign, easy and proficient way for the synthesis of copper nanoparticles. The green synthesised copper nanoparticles were characterized by UV-Visible spectroscopy, FT-IR, XRD, SEM, TEM and their antimicrobial activity was investigated. From UVVisible spectrophotometer result was confirmed the reduction of copper sulphate to copper nanoparticles. FTIR analysis was confirmed the bending vibrations and stretching bonds present in the sample. Spherical shape was finding out by XRD and the size of the particle was analyzed with the help of Scanning Electron Microscopy and it was an average size of 23.6 - $41.2 \mathrm{~nm}$. The antibacterial activity for the 
synthesised copper nanoparticles was confirmed by the antibacterial activity experiment against Escherichia coli gram-negative and Bacillus subtilis gram-positive bacteria by agar well method and the maximum zone of inhibition was higher in grampositive bacteria compared to gram-negative bacteria. The green synthesised copper nanoparticles proved to be potential candidates for medical application antimicrobial activity is highly essential.

\section{REFERENCES}

[1]. Choi, Hyungsoo, and Sung-Ho Park. "Seedless growth of free-standing copper nanowires by chemical vapor deposition." Journal of the American Chemical Society 126, no. 20 (2004): 6248-6249.

[2]. Huang, Lina, Heqing Jiang, Jisheng Zhang, Zhijun Zhang, and Pingyu Zhang. "Synthesis of copper nanoparticles containing diamond-like carbon films by electrochemical method." Electrochemistry Communications 8, no. 2 (2006): 262-266.

[3]. Joshi, S. S., S. F. Patil, V. Iyer, and S. Mahumuni. "Radiation induced synthesis and characterization of copper nanoparticles." Nanostructured materials 10, no. 7 (1998): 1135-1144.

[4]. Dhas, N. Arul, C. Paul Raj, and A. Gedanken. "Synthesis, characterization, and properties of metallic copper nanoparticles." Chemistry of materials 10, no. 5 (1998): 1446-1452.

[5]. Hashemipour, Hassan, Maryam Ehtesham Zadeh, Rabee Pourakbari, and Payman Rahimi. "Investigation on synthesis and size control of copper nanoparticle via electrochemical and chemical reduction method." International Journal of Physical Sciences 6, no. 18 (2011): 4331-4336.
[6]. Saranyaadevi, K., V. Subha, RS Ernest Ravindran, and S. A. H. A. D. E. V. A. N. Renganathan. "Green synthesis and characterization of silver nanoparticle using leaf extract of Capparis zeylanica." Asian J. Pharm. Clin. Res 7 (2014): 44-48.

[7]. Yamini SudhaLakshmi, G., Fouzia Banu, and Arumugam Ezhilarasan. "Sahadevan. Green Synthesis of Silver Nanoparticles from Cleome Viscosa." Synthesis and Antimicrobial Activity 5 (2011).

[8]. "Mitragyana parvifolia- kaim, www. Flowersofindia.net.retrieved, (2016): 11-03.

[9]. Pence, Laura E., and Mary M. Kirchhoff. "ConfChem Conference on Educating the Next Generation: Green and Sustainable Chemistry Green Chemistry and Sustainability through the American Chemical Society Education Division and Committee on Environmental Improvement." Journal of Chemical Education 90, no. 4 (2013): 510-512.

[10]. Gong, Fang, Hai-peng $\mathrm{Gu}, \mathrm{Qi}-$ tai $\mathrm{Xu}$, and Wen-yi Kang. "Genus Mitragyna: Ethnomedicinal uses and pharmacological studies." Phytopharmacology 3, no. 2 (2012): 263-272.

[11]. Saranyaadevi, K., V. Subha, RS Ernest Ravindran, and S. Renganathan. "Synthesis and characterization of copper nanoparticle using Capparis zeylanica leaf extract." Int J Chem Tech Res 6, no. 10 (2014): 4533-4541.

[12]. Das, Sreemanti, Jayeeta Das, Asmita Samadder, Avijit Paul, and Anisur Rahman KhudaBukhsh. "Efficacy of PLGA-loaded apigenin nanoparticles in Benzo [a] pyrene and ultraviolet-B induced skin cancer of mice: Mitochondria mediated apoptotic signalling cascades." Food and chemical toxicology 62 (2013): 670-680. 
[13]. Shanmuga Priya, K., A. Gnanamani, N. Radhakrishnan, and Mary BABU. "Antibacterial activity of Datura alba." Indian drugs 39, no. 2 (2002): 113-116.

[14]. Ahmad, Naheed, Seema Sharma, V. N. Singh, S. F. Shamsi, Anjum Fatma, and B. R. Mehta. "Biosynthesis of silver nanoparticles from Desmodium triflorum: a novel approach towards weed utilization." Biotechnology Research International 2011 (2011).

[15]. Li, Zhi, Daeyeon Lee, Xiaoxia Sheng, Robert E. Cohen, and Michael F. Rubner. "Two-level antibacterial coating with both release-killing and contact-killing capabilities." Langmuir 22, no. 24 (2006): 9820-9823.

[16]. Donda, Manisha R., Karunakar Rao Kudle, Jahnavi Alwala, Anila Miryala, B. Sreedhar, and MP Pratap Rudra. "Synthesis of silver nanoparticles using extracts of Securinega leucopyrus and evaluation of its antibacterial activity." Int J Curr Sci 7 (2013): 1-8.

[17]. Joseph, Akansha Treeza, P. Prakash, and S. S. Narvi. "Phytofabrication and Characterization of Copper Nanoparticles Using Allium Sativum and its Antibacterial Activity." IJSET 4 (2016): 463-473.

[18]. S.D. Ashtaputrey, P.D. Asthaputry and Neha Telane, green synthesis and characterisation of copper nanoparticles derived from Murraya Koenigii leaves extract, Journal of Chemical and Pharmaceutical Sciences, 2017, 10(3), 12881291.

[19]. Valli, G., and S. Geetha. "Green Synthesis of Copper Nanoparticles using Cassia Auriculata Leaves Extract." International journal of technochem. Research 2, no. 1 (2016): 05-1

[20]. Kulkarni, V., and P. Kulkarni. "Synthesis of copper nanoparticles with aegle marmelos leaf extract." Nanosci Nanotechnol 8 (2014): 401404 .
[21]. Joseph, Akansha Treeza, P. Prakash, and S. S. Narvi. "Phytofabrication and Characterization of Copper Nanoparticles Using Allium Sativum and its Antibacterial Activity." IJSET 4 (2016): 463-473.

[22]. Singh, Ashwani Kumar, Mahe Talat, D. P. Singh, and O. N. Srivastava. "Biosynthesis of gold and silver nanoparticles by natural precursor clove and their functionalization with amine group." Journal of Nanoparticle Research 12, no. 5 (2010): 1667-1675

\section{Cite this article as :}

Dr. Shaileshkumar Chandubhai Kotval, "Green Synthesis of Copper Nanoparticles Using Mitragyna Parvifolia Bark Extract and its Antimicrobial Study", International Journal of Scientific Research in Science and Technology (IJSRST), Online ISSN : 2395-602X, Print ISSN : 2395-6011, Volume 6 Issue 5, pp. 26-33, September-October 2019. Available at doi : https://doi.org/10.32628/IJSRST19658 Journal URL : http://ijsrst.com/IJSRST19658 